\title{
Bullying and harassment rife in Manchester unit, report says
}

\author{
Zosia Kmietowicz London
}

Management and clinical staff at a facility in Manchester for elderly people with mental health problems have been accused of neglect by allowing the long term physical and emotional abuse of their most vulnerable patients.

Patients on Rowan ward, a mental health unit for old people run by Manchester Mental Health and Social Care Trust, endured "old fashioned" and "regimented nursing care," says a report from the Commission for Health Improvement.

Abuse at the unit, which closed in December 2002, took several forms and included hitting, stamping on feet, intimidating language, withholding food, and playing on patients' known anxieties, says the report.

The commission was called in to investigate claims of abuse at the same time that the trust decided to close the ward because it could no longer guarantee the safety of the patients there.
The investigation in Manchester is the third into the care of vulnerable elderly people around the country, and inspectors fear that many similar situations exist elsewhere.

Acting chief executive of the commission, Jocelyn Cornwell, said, "The care received by vulnerable older people on Rowan ward was unacceptable, but we are seriously concerned that circumstances surrounding this investigation are not unique.

"The care of older people nationally is very concerning. NHS managers and commissioners should take a good look at this report and ensure recommendations are embedded in their own services. Organisations must learn to monitor closely what happens on older people's wards and open up wards to external visitors and patients' advocates."

Rowan ward had many of the known risk factors for abuse, including a poor, institutionalised environment, low staffing levels, high use of bank and agency staff, little staff development, poor supervision, lack of incident reporting, and a closed and inward looking culture, said the report.

To improve patients' health and safety the commission recommends that trusts, strategic health authorities, and other NHS bodies should develop a reporting system for when things go wrong and ensure that staff practise modern evidence based care.

The trust at the centre of the report has pledged that its programme of internal changes, which was set up after the report was commissioned, will ensure that incidents such as those reported on Rowan ward never happen again.

The trust has recently reviewed its nursing practice and has introduced training for staff working on wards for elderly patients. It has also set up a central incident reporting system. Between February 1999 and July 2002 no records of any incident on Rowan ward were kept, and serious injuries such as scalds, bruises, and patients leaving the ward without consent went unacknowledged.

A new medicines management policy is also being employed to avoid unqualified staff handing out drugs, as allegedly happened in the past.

Sally Chisholm, head of mental health commissioning for Manchester, said on behalf of the three primary care trusts and the local authority: "There was a serious systems failure that allowed these events to happen, and all the organisations involved bear some responsibility."

The report on Rowan ward is at www.chi.nhs.uk

\section{Doctor sentenced for manslaughter of leukaemia patient}

Clare Dyer legal correspondent, BMJ

A specialist registrar who supervised the mistaken injection of a cytotoxic drug into the spine of a teenager with leukaemia was sentenced to eight months in prison on Tuesday after pleading guilty to manslaughter

Feda Mulhem changed his plea as a retrial was about to begin at Nottingham Crown Court. An earlier trial had to be abandoned because of his ill health (BMJ 2003;327:123).

Dr Mulhem, 36, who trained in Damascus, was also sentenced to an additional 10 months' imprisonment after pleading guilty to assaults on his wife and other people. Nine months of the total 18 months' prison sentence were suspended, and he walked free because he has already spent more than his immediate prison term in custody on the assault charges.

He was only three days into his first post as a specialist registrar in haematology at Queen's Medical Centre, Nottingham, in January 2001 when he supervised a senior house officer in injecting vincristine into the spine of Wayne Jowett, 18, who was in remission from leukaemia. The drug is meant to be injected intravenously and is fatal if injected into the spine.

Within 15 minutes both doc-

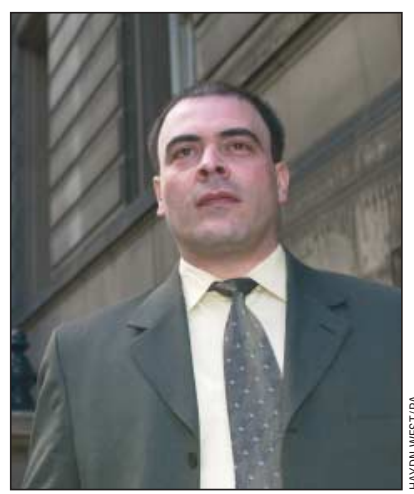

Dr Feda Mulhem

tors had realised their mistake, but it was too late to save the teenager's life. Dr Mulhem later told police he thought he was administering methotrexate, which is properly injected into the spine.

The senior house officer had been in the department for only five weeks, and neither doctor had been given training in administering cytotoxic drugs. Though the senior house officer checked twice to be certain of Dr Mulhem's instructions, he was told to go ahead.

The prosecution accused $\mathrm{Dr}$ Mulhem of failing to check the patient's haematology chart, failing to see which drug should have been administered, and failing to check instructions on the syringe that vincristine should only be injected into a vein.

He later underwent retraining as a specialist registrar at Nottingham City Hospital. Similar blunders involving vincristine have been made 14 times in Britain since 1985 (BMJ 2001;322:257). Four other doctors have been prosecuted in Britain for the same mistake but all were eventually cleared. 